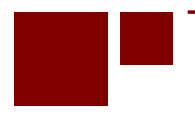

C E N T E R for RETIREMENT RES E A R C H at BOSTON COLLEGE

\title{
THE EFFECT OF MEDICARE PART D ON EVERGREENING, GENERIC ENTRY, AND DRUG PRICES
}

Geoffrey T. Sanzenbacher and Gal Wettstein

CRR WP 2019-8

May 2019

\author{
Center for Retirement Research at Boston College \\ Hovey House \\ 140 Commonwealth Avenue \\ Chestnut Hill, MA 02467 \\ Tel: 617-552-1762 Fax: 617-552-0191 \\ https://crr.bc.edu
}

Geoffrey T. Sanzenbacher is the associate director of research at the Center for Retirement Research at Boston College (CRR). Gal Wettstein is a research economist at the CRR. The research reported herein was performed pursuant to a grant from The Commonwealth Fund. The opinions and conclusions expressed are solely those of the authors and do not represent the opinions of The Commonwealth Fund or Boston College.

(C) 2019, Geoffrey T. Sanzenbacher and Gal Wettstein. All rights reserved. Short sections of text, not to exceed two paragraphs, may be quoted without explicit permission provided that full credit, including (C) notice, is given to the source. 


\begin{abstract}
About the Center for Retirement Research
The Center for Retirement Research at Boston College, part of a consortium that includes parallel centers at the National Bureau of Economic Research, the University of Michigan, and the University of Wisconsin-Madison, was established in 1998 through a grant from the U.S. Social Security Administration. The Center's mission is to produce first-class research and forge a strong link between the academic community and decision-makers in the public and private sectors around an issue of critical importance to the nation's future. To achieve this mission, the Center sponsors a wide variety of research projects, transmits new findings to a broad audience, trains new scholars, and broadens access to valuable data sources.
\end{abstract}

Center for Retirement Research at Boston College

Hovey House

140 Commonwealth Ave

Chestnut Hill, MA 02467

Tel: 617-552-1762 Fax: 617-552-0191

https://crr.bc.edu

Affiliated Institutions:

The Brookings Institution

Mathematica - Center for Studying Disability Policy

Syracuse University

Urban Institute 


\begin{abstract}
Medicare Part D was established to expand outpatient prescription drug coverage to all seniors. An obvious effect of Part D was to improve the well-being of those who gained coverage by reducing their exposure to drug costs. But, the law also boosted demand for drugs used by those ages 65 and over, and extended the bargaining power enjoyed by commercial plans vis a vis drug manufacturers to the Part D market. Both these changes could give branded drug manufacturers extra incentive to protect their products' monopoly status through so-called "evergreening," with unforeseen impacts on the generic drug market and ultimately on prices. While work to date has generally found that Part D decreased prices through increased insurer bargaining power, that literature focused on the few years after Part D launched, a time before the effect of increased evergreening or decreased generic entry could be felt. This paper takes a longer view of how Part D has affected evergreening, generic entry, and ultimately drug prices in a difference-in differences design that compares these outcomes for drugs used frequently by those ages 65 and over to those used infrequently by this population. The results show that Part D increased evergreening and reduced generic entry, and suggest that these effects are associated with higher prices. However, Part D's overall effect on drug prices is still negative, as the impact of insurer bargaining power apparently more than offsets the effect of more limited supply-side competition.
\end{abstract}




\section{Introduction}

Drug manufacturers have incentives to maintain monopoly status for their products as long as possible. One way to accomplish this goal is through a strategy known as “evergreening." This practice lengthens the time a drug manufacturer maintains the exclusive ability to market a version of its product by obtaining additional FDA approvals or patents that modify the original product. ${ }^{1}$ For example, a product may be evergreened by obtaining approval for an extended release version of the original drug, or a version with a different strength, innovations that may have clinical value (e.g., by improving adherence to a treatment regime) but do not represent a fundamentally new development. ${ }^{2}$ This new version does not stop a manufacturer of a generic version of the drug from entering against the original product, but it does mean that the generic has to compete with a product that is likely being marketed as an improved version, potentially limiting the benefits of entry. ${ }^{3}$ Given that the passage of the Medicare Modernization Act of 2003 and the subsequent launch of Medicare Part D changed the pharmaceutical landscape substantially, a logical question is how this policy intervention affected the behavior of drug manufacturers with respect to evergreening.

The answer to this question is important to the extent that if evergreening discourages generic entry or enables a branded drug to hold onto its market share, the ultimate impact could be felt in higher drug prices. Yet, the impact of Part D on evergreening, generic entry, and prices is theoretically ambiguous. On the one hand, the introduction of Part D made those older consumers who gained coverage less price sensitive and thus increased demand for drugs. ${ }^{4}$ This effect would seem to increase the incentive for manufacturers to evergreen and maintain exclusivity over this larger market, while simultaneously increasing the incentive for generic manufacturers to challenge this exclusivity. ${ }^{5}$ On the other hand, because Part D subsidizes the purchase of private insurance, it also increases insurers' bargaining power in the pharmaceutical market relative to manufacturers. ${ }^{6}$ To the extent this increased bargaining power results in lower

\footnotetext{
${ }^{1}$ Gaudry (2011) provides evidence that this practice is common.

${ }^{2}$ The term "evergreening" is sometimes used in a derogatory fashion but in this paper is meant only to imply the extension of a product's market protections beyond the original patent and exclusivity period.

${ }^{3}$ Throughout the paper, the term "drug" refers to the active ingredient and the two are used synonymously.

${ }^{4}$ Prior research has clearly established that Part D increased demand for prescription drugs. For example, see Engelhardt and Gruber (2011) and Wettstein (2018).

${ }^{5}$ For evidence that generic firms are more likely to challenge evergreening-derived exclusivity, see Hemphill and Sampat (2012).

${ }^{6}$ See Lakdawalla and Lin (2015) for an excellent discussion.
} 
prices, branded drug manufacturers may have less to gain from maintaining exclusivity than in the past, and generic manufacturers would likewise have less incentive to launch their own products. This paper aims to empirically investigate which effect dominates, examining how Part D affected evergreening, generic entry and ultimately drug prices.

Despite the changes effected by Part D on manufacturer incentives, it is not obvious that manufacturers would strategically respond to Part D by extending exclusivities further. The cost of developing a new drug is so great (estimated at between $\$ 800$ million and $\$ 2.6$ billion per drug in 2013 dollars, DiMasi, Grabowski, and Hansen 2016) and the profit involved in maintaining a monopoly on it is so large that evergreening decisions might be infra-marginal: manufacturers may do their utmost to extend monopolies regardless of policy changes. One reason for optimism regarding the ability of policy to affect such behavior is that research and development $(R \& D)$ costs are high even for drugs that have already been approved for marketing. Post-approval R\&D accounts for 11 percent of total R\&D costs, around $\$ 466$ million per drug (in 2013 dollars). Thus, drug companies face a real trade-off between evergreening activities and other investment opportunities, which may afford policy some impact in shaping the strategic behavior of manufacturers. This paper will shed light on whether policy has such an impact.

The major methodological barrier in investigating how manufacturers responded to Part $\mathrm{D}$ is that, aside from the new program, secular forces may also have affected the behavior of branded and generic drug manufacturers, as well as drug prices. For example, if the pipeline for new drugs was drying up at the same time Part D was launching, it may have encouraged branded companies to engage more frequently in evergreening, given generic entrants more products with expiring patents to enter against, and potentially driven prices down. ${ }^{7}$ Failure to control for these secular forces would misattribute price effects to Part D. To get around this issue, the project uses the Medical Expenditure Panel Survey (MEPS) merged onto the complete set of drug approvals from 1984 to 2016 to perform a difference-in-differences analysis. Specifically, the analysis compares the pre- and post-Part D periods separately for drugs used primarily by those ages 65 and over and drugs used mostly by those 65 and under. Since many drugs are used by both age groups, the approach takes the form of a "dose-response" analysis, interacting the share of a drug's pre-reform uses by those over 65 with a post-Part $\mathrm{D}$ indicator to

\footnotetext{
${ }^{7}$ For one reason, because new ideas are becoming harder to generate. See, for example, Bloom et al. (2017).
} 
tease out the effect of Part D on the relevant outcome. In this analysis, the drugs used primarily by those 65 and under serve as the control for any secular trend in evergreening, generic entry, or prices. $^{8}$

The quasi-experimental findings suggest that Part D has significantly increased the frequency of evergreening on the part of branded manufacturers and decreased the incidence of generic entry. However, while both of these forces would seem to push towards higher prices, in fact, prices fell for drugs used frequently by seniors relative to other products, likely due to the increased bargaining power Part D gave to insurers vis-a-vis drug manufacturers. This result does not mean that the increase in evergreening had no impact. Descriptive results supplementing the quasi-experimental approach show that drugs with an evergreen exclusivity were 10 percent more expensive than similar drugs without such protections. While the finding that overall prices have fallen due to Part D is consistent with work using earlier data, the finding that evergreening has increased and that these exclusivities positively affect prices is new to the literature. $^{9}$

The rest of the paper is organized as follows. The next section offers background on the practice of evergreening and on how Part D may affect it. The third section discusses the data and empirical approach, and the fourth presents results. The final section concludes that the introduction of Part D does seem to have spurred an increase in evergreening and a decline in generic entry and these effects offset some of the price declines. Policymakers may want to consider ways to limit the practice of evergreening in cases where patient gains from the altered product are unclear. Still, the paper finds - like others before it - that Part D decreased prices on net.

\section{Background}

This section describes the notion and incidence of evergreening before examining the launch of Medicare Part D, what is known about its effect on pharmaceutical markets, and what that might mean for evergreening specifically.

\footnotetext{
${ }^{8}$ This design is very similar to the one used in Duggan and Scott Morton $(2010,2011)$.

${ }^{9}$ See Duggan and Scott Morton $(2010,2011)$ and Lakdawalla and Yin (2015).
} 


\section{Evergreening}

Obtaining FDA approval to market a new drug is a costly endeavor, both from a time and a dollar perspective. ${ }^{10}$ To encourage drug manufactures to undertake this process, the government grants drug makers two kinds of protections that prevent generic companies from entering the market and competing against branded products, allowing them to charge prices well above marginal cost for a period of time. The first type of protection is a patent, which is typically applied for early in a drug's development, prior to FDA approval, and lasts 20 years from the time of issuance. While generic drug companies can launch their own product before a brand's patents expire, they either have to prove in court that the patents are invalid, or they must launch "at risk" of being forced to pay retribution for damage done to the branded company if the patent is found to be violated. The second type of protection - FDA-granted exclusivity periods - are even more restrictive, and imply that no generic drug manufacturer can gain approval by the FDA to market a copy of the drug during the period covered. For example, an original drug approved by the FDA typically gets a five-year exclusivity period or, if it is for a rare condition, seven years. ${ }^{11}$ Combining, these two sources of protection means that a new drug has a monopoly for a substantial period before a generic product enters, after accounting for the time between the initial patent and first approval. ${ }^{12}$

One strategy to extend a drug's life pre-generic competition is to seek additional patents or exclusivities that cover a narrower concept than the original - often referred to as evergreening because it ensures patents or exclusivities remain in place. ${ }^{13}$ Specifically, when a company evergreens a drug, any additional patent lasts 20 years from issuance and any exclusivity lasts three years. ${ }^{14}$ For example, the anti-depressant Paxil® received 10 such ancillary patents, including one for a controlled-release version of the original drug - a common method of evergreening. ${ }^{15}$ This controlled release version could then be marketed without generic competition as an improvement over both the original branded product and any generic competitors.

\footnotetext{
${ }^{10}$ For example, Dimasi et al. (2016) report development costs ranging from $\$ 800$ million to $\$ 2.6$ billion, and Van Norman (2016) reports a lag of 12 years between pre-clinical testing and approval.

${ }^{11}$ See Food and Drug Administration (2015).

12 Typically, a new drug has about 12 to 16 years of life as a monopoly. See Kesselheim, Sinha, and Avorn (2017).

${ }^{13}$ For an excellent discussion, see Gaudry (2011).

${ }^{14}$ Again, see Food and Drug Administration (2015).

${ }^{15}$ See Huskamp et al. (2008). See Fowler (2017) for a discussion of different types of "line extensions" a branded drug manufacturer may pursue.
} 
While the patent and/or exclusivity would not cover the original product - e.g., a generic could launch against the non-extended release version of the drug - the new patent or exclusivity could increase prices for drugs in two ways. First, an evergreen patent or exclusivity could deter generic entry by ensuring a product being pushed as superior by the branded company is still in the market. Or evergreening could increase prices by maintaining some brand share for the altered version of the product, even if a generic enters against the original. ${ }^{16}$ So, while debate exists about the clinical benefits of these evergreened products (through, for example, improved drug compliance due to needing fewer pills), the general concern is that by preventing generic entry or maintaining brand market share, the practice increases prices. ${ }^{17}$

If a positive effect on prices existed, it would be troubling since the evidence suggests evergreening is becoming more common. Gaudry (2011) notes that drugs approved by the FDA toward the latter end of the 2000-2010 period were more likely to be evergreened with three years of exclusivity than they were at the beginning of the decade. Similarly, Feldman (2017) shows that the probability of an existing drug receiving a new patent doubled between 2005 and 2015. Hemphill and Sampat (2012) note that drug companies seem to be strategically evergreening drugs that have higher sales. Despite the fundamental change in drug markets brought on by Medicare Part D during the period examined by these studies, no research has focused on Part D's role in fueling any increase in evergreening and any subsequent effect on generic entry or prices. ${ }^{18}$

\section{Medicare Part D}

Medicare Part D was established by the Medicare Prescription Drug, Improvement, and Modernization Act (MMA), enacted in December 2003. When Part D launched in 2006, it represented the largest reform in Medicare's history. Prior to Part D, Medicare insured seniors only for drugs administered in a medical setting or through some alternative arrangement (like some Medigap and Medicare Advantage plans), leaving many seniors uninsured for outpatient

\footnotetext{
${ }^{16}$ Alkhafaji et al. (2012) notes that a high market share of citalopram/escitalopram went to branded escitalopram, even though a generic version of citalopram was available.

${ }^{17}$ For a study comparing efficacy in an original versus an evergreened version of a product, see Alkhafaji et al. (2012), which found limited evidence that the evergreened version of citalopram was an improvement. For a paper suggesting that this practice does little to advance patient care and instead represents gaming by pharmaceutical companies, see Feldman (2017).

${ }^{18}$ Hemphill and Sedat (2015) suggests that evergreening may not prevent generic entry, in which case any impact on drug prices would come through the maintenance of brand share.
} 
prescription drugs. ${ }^{19}$ As intended, Part D has increased the coverage of seniors (Engelhardt and Gruber 2011), leading to substantial welfare gains (Wettstein 2019), as well as spurring new drug innovation (Blume-Kohout and Sood 2013).

Although no research has focused on Part D's role in encouraging evergreening, previous studies have explored its role in affecting final prices. For example, Lakdawalla and Yin (2015) show that Part D lowered prices significantly as early as 2007, mostly by increasing insurers' bargaining power. Duggan and Morton $(2010,2011)$ use data through 2009 and also find a reduction in prices for branded drugs. However, these studies focused on the very early years of the program, probably before any change in evergreening behavior by manufacturing firms could have had an impact. Furthermore, it is possible that Part D decreased average prices but that evergreening partially offset the decline. In particular, since Lakdawalla and Yin suggest the mechanism for decreased prices is increased bargaining power by insurers, brand manufacturers might use evergreening to maintain some of their monopoly power and restore lost leverage over insurance companies. It is worth noting that any increase in insurers' power or increased use of evergreening would strike a double blow against generic manufacturers, which already had less power in insurer negotiations and would face an increase in the existence of evergreened products. $^{20}$

\section{Data and Methodology}

This section first describes the data used to determine whether a particular drug has been evergreened as well as the data used to determine that product's exposure to Part D and its price. The section then turns to the difference-in-differences methodology employed to study Part D's effect on evergreening, generic entry and price.

\section{Data}

This analysis is based on two broad sources of data: 1) FDA data on drug approvals and the exclusivities and patents associated with those approvals; and 2) data from the Medical Expenditure Panel Survey (MEPS).

\footnotetext{
${ }^{19}$ Almost half of Medicare beneficiaries lacked drug coverage for the full year before Part D (Cubanski et al. 2005).

${ }^{20}$ In fact, often insurers do not negotiate with generic manufacturers at all, leaving this process to the distributors.
} 


\section{FDA Data}

To identify drugs that are evergreened in a given year, this paper relies on the database of drug approvals maintained online at Drugs@FDA. This database includes over 16,000 unique approvals for original products, changes to those products, and generic entrants going back to $1984 .^{21}$ The database contains information on the date of approval, the product name, the active ingredient (or generic name), the drug's manufacturer, and the type of submission. The paper defines an approval as evergreening if the type of submission was "Type 3 - New Dosage Form," "Type 3 - New Dosage Form and Type 4 - New Combination," or "Type 4 - New Combination." 22 In these cases, the label of evergreening reflects the fact that these approvals do not represent a new drug, but rather the adjustment of an existing product or the creation of a new product from two active ingredients that already have approval. It is not meant to imply that the new approval has no clinical value.

In addition to the basic approval data, the paper also uses data on those approvals made available through a Freedom of Information Act request to the Food and Drug Administration. This request led to the acquisition of two pieces of information: 1) the existence and expiration of any patents associated with an approval; and 2) the exclusivities granted by the FDA associated with those approvals and the exclusivities' expirations. These data are useful in controlling for factors beyond Part D that could affect both evergreening and generic entry. For example, if coincidental to the creation of Part D, many drugs used by older individuals had patents or exclusivities expiring, then evergreening may uptick naturally. This would have the side effect of also triggering generic entry (against the original product losing exclusivity, for example). Controlling for the timing of patent and exclusivity expiration helps improve the precision of the estimation of any effect of Part D on either evergreening or generic entry. The existence of an exclusivity associated with an evergreening approval will also be an important control in the pricing regression, as one way these approvals could affect price is by taking advantage of brand loyal consumers who want to use the altered version of the brand.

\footnotetext{
${ }^{21}$ The data technically contain generic approvals, rather than information on whether or not such generic versions are marketed. However, there would seem to be no reason to obtain a generic approval besides a plan to enter the market, and it is impossible to enter the market with a generic version without such an approval. Therefore, the analysis treats generic approval and generic entry as equivalent.

22 This approach is similar to Fowler (2017), who also includes approvals labeled as "Type 2 - New Active Ingredient" as a type of "line extension." Because a new active ingredient seems like a major change, we do not include this as evergreening.
} 
One thing worth noting is that the patent data could also be used, in theory, to identify evergreening, as Hemphill and Sampat (2012) did. After all, obtaining a patent for a small modification to a product could scare generic manufacturers away from entering, for fear of violating that patent. However, for purposes of this paper, the actual FDA approval seems more relevant, since it actually gives license to the company to market a new version of its product. The existence of patent protection would only indirectly impact generic entry and price. Furthermore, Hemphill and Sampat show that evergreening patents themselves have only limited utility in extending market protections, since they are disproportionately challenged by generic entrants. The exclusivity gained by an FDA approval, on the other hand, categorically prevents sale of the modified product by generic competitors.

\section{MEPS Data}

In addition to data on evergreening, the empirical approach also requires a measure of a drug's price and its exposure to Part D. For this purpose, the paper turns to the MEPS, a survey that began in 1996 and was conducted annually through 2016 by the U.S. Agency for Healthcare Research and Quality. The MEPS sample consists of between 20,000 and 40,000 individuals per year and contains a variety of information on individual demographics, and information on various medical conditions, their treatments, and the cost of the treatments. The most relevant portion of the MEPS for this paper is the "Prescribed Medicines File," which contains information on drugs prescribed (e.g., strength, days supplied, etc.), the reimbursements for those drugs from various payers (e.g., the individual, private insurers, government insurers like Medicare and Medicaid, the VA, etc.), and the drug's therapeutic class. These data can be merged onto the basic demographic portion of the MEPS to determine whether a given prescription was given to someone over age 65 - and likely affected by Medicare Part D.

Once the prescription drug data are merged with the recipient's age, the data are collapsed to the drug-year level (i.e., combining both brand and generic prescriptions). The information maintained in this collapsed dataset includes the name of the active ingredient, the number of prescriptions in a given year, the share of those prescriptions to people ages 65 and over, the overall amount paid per prescription, and the amount reimbursed per prescription for key payers. These data are then merged by active ingredient onto the complete history of drug approvals, exclusivities, and patents, removing any approved active ingredient that has no 
prescriptions in the MEPS. Only drugs approved during or prior to 2003 are kept, to ensure that the measure of exposure to Part D is exogenous to the reform itself. The final dataset includes 299 drugs per year, for a total of 4,415 drug-year observations in the basic regressions.

In addition to the MEPS data, each of these drugs has a history of up to 158 approvals, along with the patents and exclusivities associated with those approvals. If, in a given year, the active ingredient's history contains an evergreen approval, then that active-ingredient year is flagged accordingly, as are years with an identified generic approval. Similarly, drugs whose patents or exclusivities will expire the next year are flagged to identify periods when evergreening may be especially likely, and the year they actually expire flagged to identify years when generic entry is especially likely. Finally, drugs with an exclusivity in effect for an evergreened product are identified to see if this practice has any correlation with price.

\section{Methodology}

The analysis proceeds in three main steps. The first is a graphical analysis that begins by dividing drugs into those that, prior to passage of the MMA in 2003, had either an above the median or below the median share of their prescriptions going to individuals over age $65 .^{23}$ The share of prescriptions to over 65 year-olds is a measure of exposure to Medicare Part D, since the policy change mainly affected these individuals (see Table 1 for a description of the data with drugs divided by these groups). ${ }^{24}$ For each outcome, the analysis plots the outcome mean in every year for both the more and less Part D-exposed drugs. Discontinuous changes after 2003 in the more exposed drugs, relative to the less exposed drugs, are interpreted as reflecting the effect of the MMA on the outcome.

The goal of this graphical analysis is to provide two insights. First, the relative change in the outcome of more versus less exposed drugs in 2003 provides a visualization of the treatment effect of Part D. Second, parallel pre-trends between the two groups of drugs provide an intuitive test of the identifying assumption of the difference-in-differences: that absent the MMA, trends in evergreening, generic entry, and price would have persisted independently of how exposed drugs were to the over 65-year-old market. In other words, the graphical exercise

\footnotetext{
${ }^{23}$ Drug manufacturers would likely have begun adjusting their behavior immediately with passage of the MMA in 2003, in anticipation of the insurance changes slated to take effect starting in 2006.

${ }^{24}$ Medicare Part D also extended prescription drug coverage to individuals under age 65 if they were beneficiaries of Social Security Disability Insurance; however, this population is relatively small.
} 
will give a clue as to the final effects and also an indication for whether the empirical approach is appropriate.

The second step is to evaluate the robustness of effects indicated by the graphical approach in a regression framework. This evaluation is accomplished by framing the Part D quasi-experiment as a difference-in-differences where the treatment dimension is the intensity of exposure to the over 65-year-old market, and this treatment is assumed to have begun after 2003, following passage of the MMA. Consequently, separate regression equations estimating the effect of Part D on the likelihood of evergreening and generic entry of the following form are estimated:

$$
Y_{i, t}=\alpha+\beta D^{\prime}{ }_{i, t}+\gamma_{1} \operatorname{Post}_{t}+\gamma_{2} S_{i}+\gamma_{3} \operatorname{Post}_{t} * S_{i}+\tau_{t}+\varepsilon_{i, t}(1)
$$

where $Y_{i, t}$ is an indicator for drug $i$ having received an evergreening or generic approval in year $t$ (the effect on prices is estimated in a regression with a different form); $D_{i, t}^{\prime}$ is a vector of drugspecific characteristics; $\operatorname{Post}_{t}$ indicates the observation is occurring after 2003; and $S_{i}$ is the mean share of the drug used by those ages $65+$ in 2003 or earlier. ${ }^{25} \tau_{t}$ is a set of year fixed effects. Standard errors are clustered at the drug level. ${ }^{26}$

$D^{\prime}{ }_{i, t}$ includes the log of total spending on drug $i$ before 2006 (the year Part D's insurance actually started), as more expensive drugs present larger incentives for both evergreening and generic entry (for example, see Hemphill and Sampat 2012). It also includes, in evergreening regressions, an indicator for any patent on the drug expiring within the next year and another indicator for any exclusivity on the drug expiring within the next year, both of which capture the strategic incentives for prolonging market protections of drugs whose previous protections are about to lapse. Similarly, the generic entry regression includes indicators for whether any patent or exclusivity expired within the last year. Finally, the regressions control for the therapeutic class of drugs to capture systematic variations in competition, price, and R\&D trajectories.

The hypothesis in the analysis is that $\gamma_{3}$ is significantly greater than 0 for evergreening, i.e., that after Part D, drug manufacturers became more likely to evergreen products used

\footnotetext{
${ }^{25}$ That is, this variable is constant across years for a given drug.

${ }^{26}$ Regressions including drug fixed effects tend to display similar point estimates; however, significance is generally lost. This result is unsurprising, given the relatively small number of clusters.
} 
frequently by the Medicare population. Conversely, the sign of $\gamma_{3}$ in the generic entry regressions is unclear, as the greater demand for drugs (incentivizing entry) is potentially offset by the increased evergreening on the part of branded manufacturers, as well as by the increased market power on the demand side of the market due to consolidation of consumers through insurers.

Even if Part D is found to have increased evergreening and decreased generic entry (both effects that would suggest price increases), these reduced form estimates cannot clarify the relationship of those factors with drug prices. The constraint here is that Part D affected drug prices through multiple mechanisms, and therefore drugs' exposure to Part D does not satisfy the exclusion restriction for identifying the effects of evergreening and generic entry on prices. Nevertheless, analysis of the effect of evergreening on prices is worthwhile, both in order to better understand how Part D has impacted drug prices and to provide general, if descriptive, associations between evergreening exclusivity, generic competition, and prices. A relationship between evergreening and prices has not been established in the literature to date.

To analyze the relationship between Part D, evergreening, and prices, the third step in the empirical approach is to estimate variants of equation (1) that include modified controls: instead of expiration of patents and exclusivity, the regression controls for whether drug $i$ was covered by an evergreening exclusivity in year $t$. It further controls for the number of generic drug approvals that had been granted to drug $i$ by year $t$. Finally, it controls for the price of the branded drug up to the entry of the first generic version, as a cleaner control in this context for the monopoly value of the drug. These changes yield regression equations of the following form, estimating the effect of Part D on price, as well as the association of evergreening and generic entry with price:

$$
\begin{aligned}
& Y_{i, t}=\alpha+\beta D_{i, t}^{\prime}+\gamma_{1} \text { Post }_{t}+\gamma_{2} S_{i}+\gamma_{3} \text { Post }_{t} * S_{i}+\mu_{1} \text { Exclusivity }_{i, t}+\mu_{2} \text { Generics }_{i, t}+ \\
& \mu_{3} \operatorname{Ln}\left({\text { Brand } \text { Price }_{i}}\right)+\tau_{t}+\varepsilon_{i, t}(2)
\end{aligned}
$$

$Y_{i, t}$ will be log of payments per prescription of drug $i$ in year $t$, either total payments or reimbursements by particular payers (out-of-pocket spending, Medicare, Medicaid, or private insurers). In this analysis, the hypothesized sign of $\gamma_{3}$ is negative, consistent with, for example, Duggan and Scott Morton (2010). In particular, if indeed evergreening increases due to Part D, 
and generic entry declines, then holding those elements constant should yield even more negative effects of Part D on prices than found in previous work. In addition, it is hypothesized that $\mu_{1}$ will be positive, and that $\mu_{2}$ will be negative, since it is expected that evergreening will allow brand manufacturers to maintain higher prices while every generic entrant is expected to increase competition and reduce monopolistic rents. The next section lays out the results of the analysis and confirms that the hypothesized relationships between the variables hold empirically.

\section{Results}

This section displays the results from the three parts of the empirical analysis: 1) the graphical analysis of drugs over time by their level of exposure to Part D; 2) the reduced form, causal regression analysis of the effect of Part D on evergreening and generic entry; and 3) a correlational analysis of evergreening exclusivity, generic competition, and price.

\section{Graphical Results}

The following figures illustrate the reduced form effect of Part D exposure on the three outcomes of interest: the prevalence of evergreening approvals, the prevalence of generic approvals, and the log of price per prescription. The drugs are classified in each figure into low and high exposure to Part D by whether their average share of prescriptions to over 65-year-olds before and in 2003 was below or above the median, respectively. While the figures display substantial noise, the linear trends by exposure are also shown, allowing for a trend break in 2003 when the MMA was enacted.

Figure 1 shows the share of drugs with evergreening approvals in the low and high exposure to Part D categories, by year. Three points are worth making here. First, the trends indicate a decline in evergreening over time for both groups of drugs, which may seem surprising in light of the earlier literature that suggested evergreening was increasing. However, this finding is at least partially due to the fact that the sample is restricted to drugs initially approved in 2003 or earlier. Consequently, the drugs observed in the figure are growing older over time, making them more likely to already have generic competitors and less likely to be evergreened. Second, the trends for high- and low-exposure drugs are parallel in the pre-2003 period. This pattern is important to assess as a test of the identifying assumption of the difference-in- 
differences research design: that in the absence of the MMA in 2003, the two groups would have continued to move in parallel.

Finally, and in contrast to the parallel movement before 2003, the trends for the two groups break discontinuously following passage of the MMA. In particular, the set of drugs most exposed to Part D experiences a larger increase in evergreening approvals than do the drugs in the less exposed group. This finding indicates that, at least descriptively, Part D led to an increase in evergreening.

Complementary patterns can be observed in Figure 2, which shows the share of drugs with generic approvals in the low- and high-exposure groups, by year. In this case, the trend for generic entry is increasing, which is again at least partially driven by the increasing longevity of the drugs in the sample. Similarly, this figure also shows parallel trends in generic approvals between the two groups before 2003 followed by a break that year, with the number of generic approvals decreasing for the drugs most used by the elderly and increasing for drugs less likely to be used by the Medicare population. This pattern of descriptive results is consistent with Part D reducing generic entry.

Finally, Figure 3 displays a similar analysis with respect to the log of price per prescription. Here, increasing prices is the trend prior to the introduction of Part D - consistent with a well-documented rise in the cost of drugs. And, once again, the drugs more and less exposed to Part D had similar increases year over year before 2003, with this parallel movement ceasing in 2003. In this case, the more exposed drugs experienced price declines following the MMA, whereas the less-exposed products saw relatively constant price increases. The finding of price declines due to Part D is consistent with previous results in, for example, Duggan and Scott Morton $(2010,2011)$. One thing worth noting is that, while it may seem counterintuitive that prices are not going up after 2003 for either group of drugs, it is again worth remembering these drug were approved prior to 2003, with generic products increasingly entering. In the full MEPS sample, drug prices do indeed rise over time at a rate of about 4.4 percent per year in the 19962016.

While these graphical analyses illustrate the patterns in the raw data, the next analysis will formalize these conclusions in a regression framework. 


\section{Reduced Form Regressions}

Tables 2 and 3 show the regression estimates corresponding to Figures 1 and 2. In both cases, the numerical estimates confirm the impression from the figures that drugs that were more exposed to Part D had an increase in evergreening, and a decline in generic entry, following enactment of the MMA. For example, controlling for exclusivity and patent protections of any sort on the drug expiring within the next year (in column 2 of Table 2), a drug that was sold only to over 65-year-olds before 2003 would have experienced an increase of 7.4 percentage points in the probability of an evergreening approval per year, on average, after 2003, relative to a drug that had been prescribed solely to consumers below age $65(\mathrm{p}<0.05)$. Given the average drug had a 32-percent exposure to the over-65 market (see Table 1), this implies that Part D increased evergreening by about 2.4 percentage points on average $(0.074 * 0.32)$ relative to the 10 -percent rate of evergreening pre-Part D.

Similarly, controlling for any exclusivity or patent having expired during the previous year (column 2 of Table 3), a drug exclusively sold to those over 65 before 2003 would have experienced a decline per year of 19 percentage points in the likelihood of having a generic approval after 2003 relative to a drug targeted exclusively to those below age $65(\mathrm{p}<0.05)$. Again, given an average exposure of 32 percent, this translates to an average effect of a 6.1percentage point decline $\left(-0.19^{*} 0.32\right)$ relative to the pre-Part D average of 14.3 percent.

For both evergreening and generic entry, the point estimates are similar across specifications with various sets of controls, including therapeutic class and brand manufacturer fixed effects (although, for evergreening, the coefficient loses statistical significance once controlling for manufacturer).

\section{The Association between Evergreening Exclusivity, Generic Competition, and Price}

Table 4 shows the estimates for the spending regressions, using the most complete set of controls corresponding to column 4 in Tables 2 and 3 (except that the control for price before 2006, the year of Part D's launch, is replaced by a control for price before the entry of any generic competitors). Thus, all columns include controls for therapeutic class and brand manufacturer, as well as year fixed effects. The columns of Table 4 correspond to 
reimbursements by different payers: total price per prescription, out-of-pocket payments, Medicaid payments, Medicare payments, and private insurer reimbursements. ${ }^{27}$

The results are broadly consistent in their signs across all payers, although magnitudes vary. For all payers and for overall cost, drugs that were more exposed to Part D experienced relative declines in price. Again, this finding is qualitatively similar to previous work showing that Part D had a negative impact on drug prices (e.g., Duggan and Scott Morton 2010, 2011). If one again applies the average 32-percent exposure, then the coefficient of $-0.593(p<0.01)$ implies that Part D decreased average drug prices by about 19 percent.

With regards to evergreening and generic competition, their associations with price go in the expected directions. For evergreening, a drug that has any product in its line covered by an evergreening exclusivity has a total price per prescription that is 9.5 percent higher on average than one without an evergreening exclusivity $(\mathrm{p}<0.05)$. This effect does not vary much by different payers, save that the effect is statistically insignificant for Medicare reimbursements, and is particularly pronounced (at 14.6 percent) for private insurers. Regarding generic competition, the regressions find that, on average, for every generic approval a drug has experienced, the products in its line are 9 percent less expensive per prescription $(p<0.01) .{ }^{28}$ Here too, the effect does not vary substantially across payers, although it might be slightly smaller for private insurers, at 7.2 percent.

A caveat to these correlational results is that they do not rely on exogenous variation in evergreening or generic approvals. This makes it impossible to say that an additional evergreening approval raises prices, or that an additional generic competitor reduces prices. This caveat is particularly true with respect to the estimated magnitudes, since the estimated signs of the effects are fairly uncontroversial theoretically. A second caution regarding these results is that the estimates are static and do not account for downstream effects on drug innovation. Even if evergreening causally increases prices, it is possible that the current level of research and development of new drugs is dependent on such high anticipated profits. The results in this

\footnotetext{
${ }^{27}$ The average payment for each payer includes only prescriptions where that payer was involved.

${ }^{28}$ This correlation is broadly similar to previous estimates in the literature, although in most cases the effect of generic entry on prices is limited to the effect on the brand-name product or on preexisting generic competitors, rather than the average price per prescription at the level of the active ingredient, as is the case here. For example, Frank and Salkever (1997) find that every generic entrant reduced the prices of other generic versions of the drug by 5.6-7.2 percent, while having a slightly positive relationship to the branded product price.
} 
analysis do not speak to any potential implications of curtailing the scope of extending monopolies on other outcomes such as the future development of new drugs.

\section{Conclusion}

Part D represented a significant expansion of prescription drug coverage. While the literature suggested that the policy decreased prices, likely due to increased insurer power, these studies were done early in the policy's history and did not reflect potential changes with respect to evergreening or generic entry. This paper's contribution is to look at these issues with additional hindsight and data on drug manufacturer responses to this policy. Furthermore, the effect of Part D on the strategic behavior of branded and generic drug manufacturers is of interest in its own right, given the emphasis that policy places on generic competition as a means of reducing drug prices.

The results confirm that Part D did, in fact, increase evergreening and decrease generic entry significantly. However, while both these effects are associated with higher prices, the effect of Part D on prices overall was negative as its aggregation of bargaining power in the hands of insurers more than offset the effect of evergreening and generic entry. Still, to the extent that evergreening increases prices and is something policymakers control, it may be worth considering limiting the practice when the drug innovation is not demonstrably beneficial to patients. 


\section{References}

Alkhafaji, Ali A., Ludovic Trinquart, Gabriel Baron, Moïse Desvarieux, and Philippe Ravaid. 2012. "Impact of Evergreening on Patients and Health Insurance: A Meta Analysis and Reimbursement Cost Analysis of Citalopram/escitalopram Antidepressants." BMC Medicine 10(1): 142-152.

Bloom, Nicholas, Charles I. Jones, John Van Reenen, and Michael Webb. 2017. “Are Ideas Getting Harder Find?” Working Paper 23782. Cambridge, MA: National Bureau of Economic Research.

Blume-Kohout, Margaret E. and Neraj Sood. 2013. "Market Size and Innovation: Effects of Medicare Part D on Pharmaceutical Research and Innovation." Journal of Public Economics 97: 327-336.

Cubanski, Juliette, Molly Voris, Michelle Kitchman, Tricia Neuman, and Lisa Potetz. 2005. "Medicare Chartbook, $3^{\text {rd }}$ Edition." Washington, DC: The Henry J. Kaiser Family Foundation.

DiMasi, Joseph A., Henry G. Grabowski, and Ronald W. Hansen. 2016. "Innovation in the Pharmaceutical Industry: New Estimates of R\&D Costs." Journal of Health Economics 47: 20-33.

Duggan, Mark and Fiona Scott Morton. 2010. "The Effect of Medicare Part D on Pharmaceutical Prices and Utilization.” American Economic Review 100(1): 590-607.

Duggan, Mark and Fiona Scott Morton. 2011. "The Medium-Term Impact of Medicare Part D on Pharmaceutical Prices and Utilization.” American Economic Review 101(3): 387-392.

Engelhardt, Gary V. and Jonathan Gruber. 2011. "Medicare Part D and the Financial Protection of the Elderly." American Economic Journal: Economic Policy 3(4): 77-102.

Feldman, Robin C. 2017. "May Your Drug Prices be Evergreen.” San Francisco, CA: UC Hastings School of Law.

Frank, Richard G. and David S. Salkever. 1997. "Generic Entry and the Pricing of Pharmaceuticals.” Journal of Economics and Management Strategy 6(1): 75-90.

Gaudry, Katherine. 2011. "Evergreening: A Common Practice to Practice to Protect New Drugs." Nature Biotechnology 29(10): 876-888.

Hemphill, C. Scott and Bhaven N. Sampat. 2012. "Evergreening, Patent Challenges, and Effective Market Life in Pharmaceuticals." Journal of Health Economics 31: 327-339. 
Huskamp, Haiden A., Julie M. Donohue, Catherine Koss, Ernst R. Berndt, and Richard G. Frank. 2008. "Generic Entry, Reformulations, and Promotion of SSRIs." Pharacoeconomics 26(7): 603-616.

Kesselheim, Aaron S., Michael S. Sinha, and Jerry Avorn. 2017. "Determinants of Market Exclusivity for Prescription Drugs in the United States." Journal of the American Medical Association: Internal Medicine 177(11): 1658-1664.

Lakdawalla, Darius and Wesley Yin. 2015. “Insurers' Negotiating Leverage and the External Effects of Medicare Part D." The Review of Economics and Statistics 97(2): 314-331.

Wettstein, Gal. 2018. "How Do Prescription Drugs Affect the Use of Other Health Services?" Issue in Brief 18-3. Chestnut Hill, MA: Center for Retirement Research at Boston College.

Wettstein, Gal. 2019 (forthcoming). "Retirement Lock and Prescription Drug Insurance: Evidence from Medicare Part D.” American Economic Journal: Economic Policy.

Van Norman, Gail A. 2016. "Drugs, Devices, and the FDA: Part 1. An Overview of the Approval Process.” JACC: Basic to Translational Science 1(3): 170-179. 
Figure 1. Share of Drugs with Evergreening Approvals, by Level of Exposure to Part D, 19962016

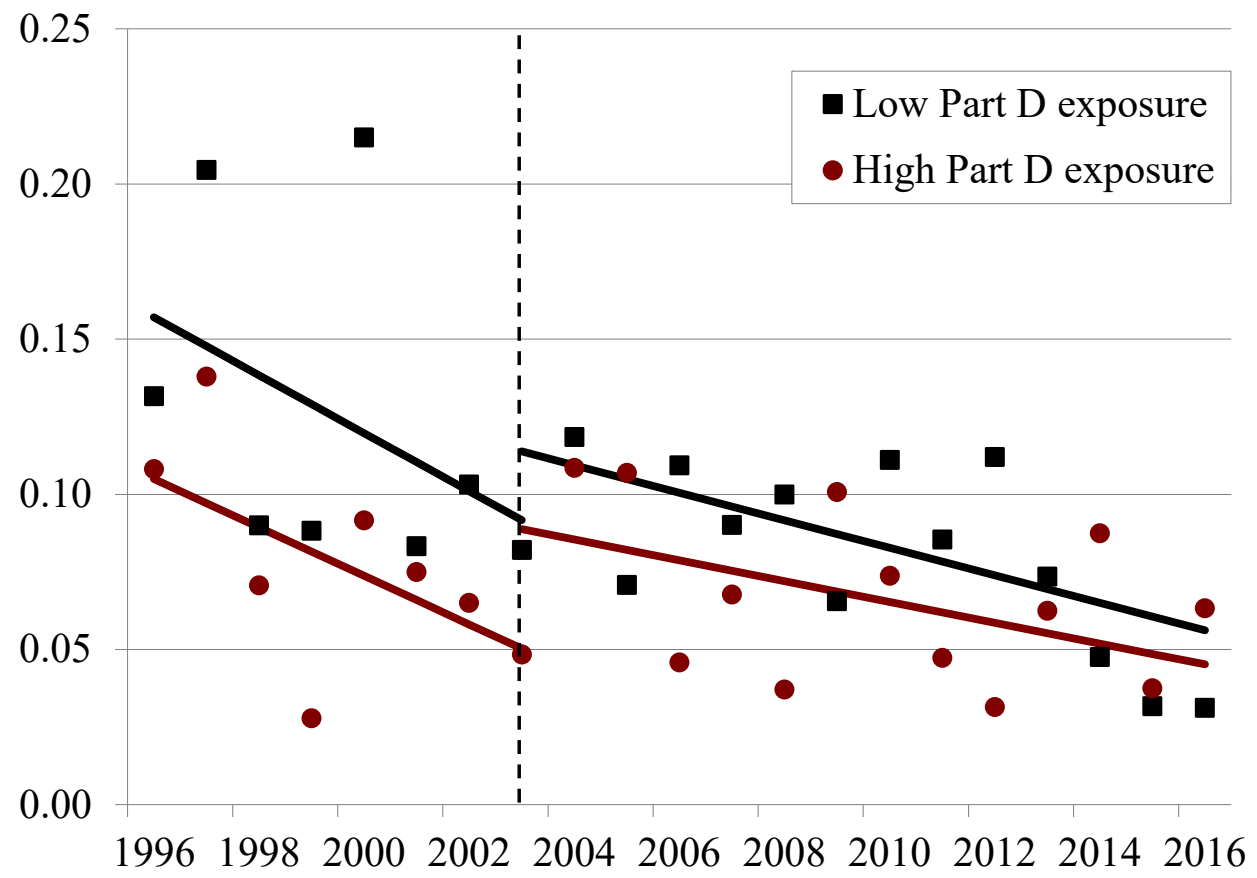

Notes: Low (high) exposure drugs are those that, in 2003 or earlier, had on average less (more) than the median share of prescriptions going to over 65 year-olds. The dashed line indicates 2003, at the end of which the MMA was enacted.

Source: Authors' calculations, using data from the 1996-2016 MEPS and the 1984-2016 FDA. 
Figure 2. Share of Drugs with Generic Approvals, by Level of Exposure to Part D, 1996-2016

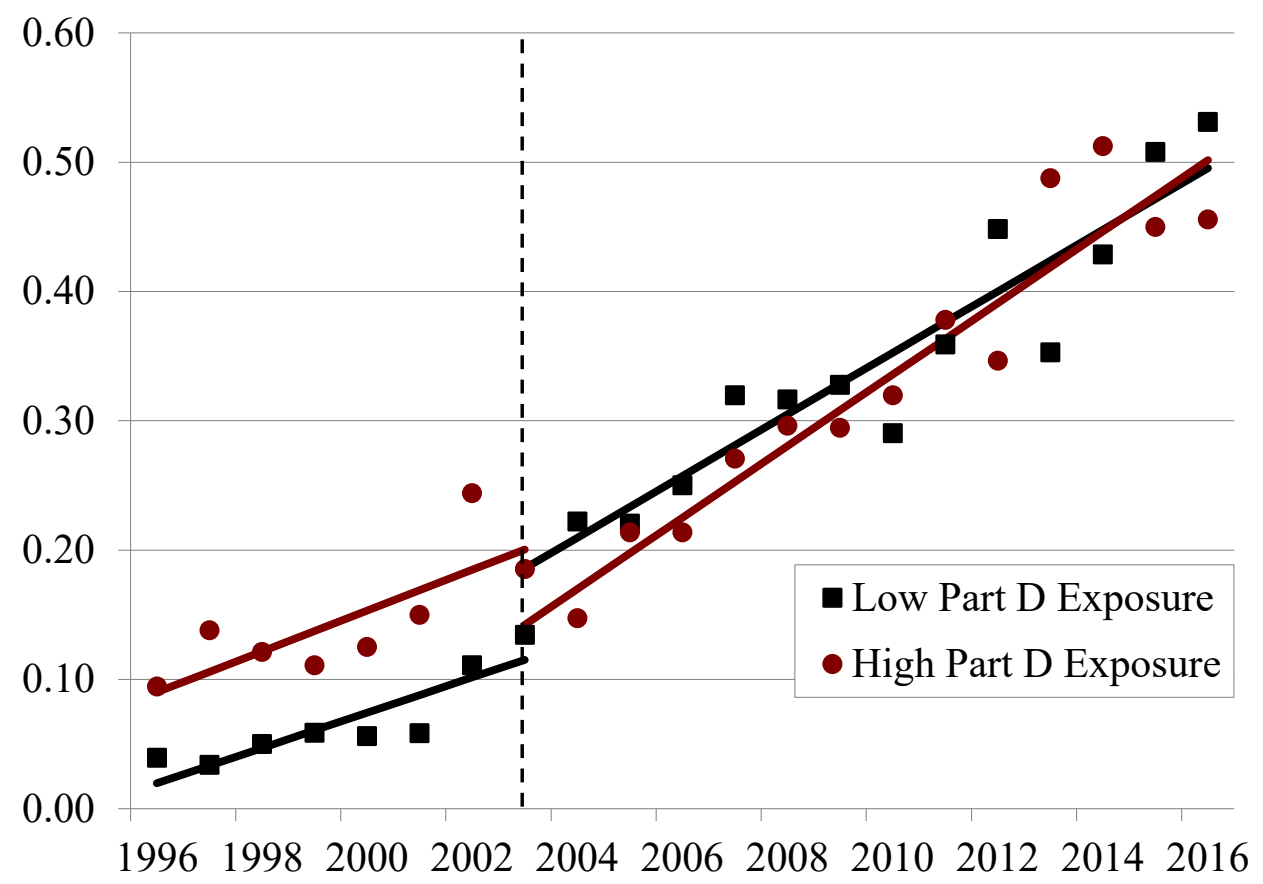

Notes: Low (high) exposure drugs are those that, in 2003 or earlier, had on average less (more) than the median share of prescriptions going to over 65 year-olds. The dashed line indicates 2003, at the end of which the MMA was enacted.

Source: Authors' calculations, using data from the 1996-2016 MEPS and the 1984-2016 FDA. 
Figure 3. Log of Total Spending per Prescription, by Level of Exposure to Part D, 1996-2016

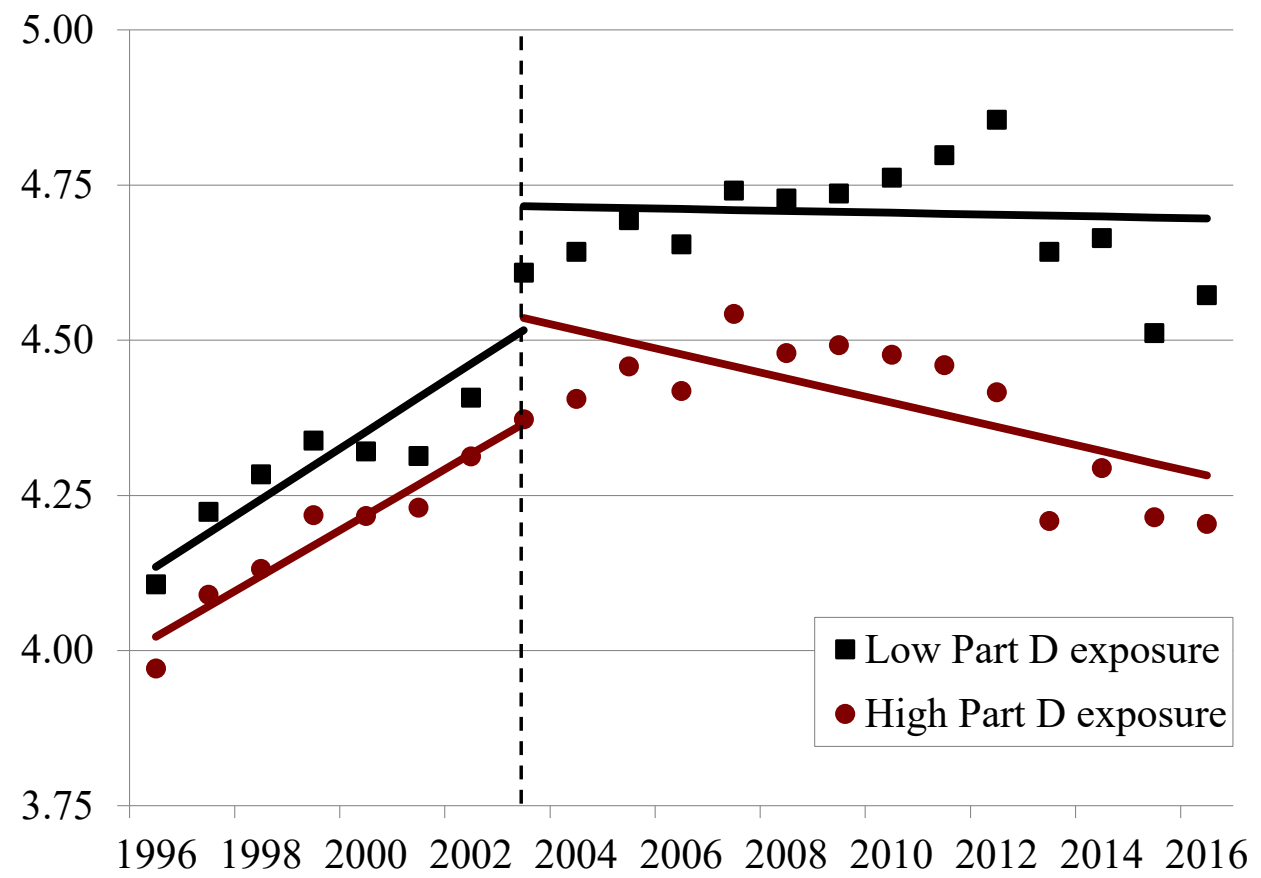

Notes: Low (high) exposure drugs are those that, in 2003 or earlier, had on average less (more) than the median share of prescriptions going to over 65 year-olds. The dashed line indicates 2003, at the end of which the MMA was enacted.

Source: Authors' calculations, using data from the 1996-2016 MEPS and the 1984-2016 FDA. 
Table 1. Descriptive Statistics for the Years 1996-2002

\begin{tabular}{lccc}
\hline & Entire sample & $\begin{array}{c}\text { Low Part D } \\
\text { exposure }\end{array}$ & $\begin{array}{c}\text { High Part D } \\
\text { exposure }\end{array}$ \\
\hline $\begin{array}{l}\text { Share of prescriptions to over 65 year- } \\
\text { olds before 2003 }\end{array}$ & 0.318 & 0.113 & 0.520 \\
Mean total spending per prescription & 96.208 & 106.348 & 86.234 \\
Any evergreening approvals in the drug- & & & \\
year & 0.103 & 0.128 & 0.079 \\
Any generic approval in the drug-year & 0.143 & 0.078 & 0.207 \\
Cardio & 0.158 & 0.006 & 0.308 \\
Central nervous system & 0.132 & 0.127 & 0.138 \\
Gastro & 0.046 & 0.025 & 0.066 \\
Anti-hyperlipid & 0.032 & 0.000 & 0.064 \\
Anti-neoplasm & 0.027 & 0.011 & 0.042 \\
Psychotherapy & 0.088 & 0.156 & 0.022 \\
Anti-infective & 0.157 & 0.296 & 0.021 \\
Respiratory & 0.046 & 0.083 & 0.010 \\
Number of drug-years & 4,415 & 2,215 & 2,200 \\
\hline
\end{tabular}

Note: The number of drug-years refers to drug years throughout the entire 1996-2016 period.

Source: Authors' calculations, using data from the 1996-2016 MEPS and the 1984-2016 FDA.

Table 2. Reduced Form Effect of Part D on Evergreening

\begin{tabular}{lcccc}
\hline & $\begin{array}{c}\text { Minimal } \\
\text { controls }\end{array}$ & Exclusivity & Therapeutic class & Manufacturer \\
\hline Post-2003*utilization of 65+ & $0.0751^{* *}$ & $0.0743^{* *}$ & $0.0635^{*}$ & 0.0618 \\
& $(0.0347)$ & $(0.0345)$ & $(0.0355)$ & $(0.0390)$ \\
Utilization of 65+ pre-2003 & $-0.147^{* * *}$ & $-0.147 * * *$ & $-0.0947^{* * *}$ & $-0.0650^{*}$ \\
& $(0.0288)$ & $(0.0287)$ & $(0.0305)$ & $(0.0359)$ \\
Log total spending before 2006 & $0.0299^{* * *}$ & $0.0296^{* * *}$ & $0.0350^{* * *}$ & $0.0368^{* * *}$ \\
& $(0.00343)$ & $(0.00333)$ & $(0.00380)$ & $(0.00501)$ \\
Any exclusivity ending in a year & - & $0.0345^{*}$ & 0.0322 & 0.0123 \\
Any patent ending within a year & - & $(0.0204)$ & $(0.0205)$ & $(0.0196)$ \\
& - & $(0.000835$ & -0.00175 & -0.00590 \\
Year FEs & Yes & Yes & $(0.0178)$ & $(0.0174)$ \\
Therapeutic class & No & No & Yes & Yes \\
Manufacturer FEs & No & No & No & Yes \\
\hline
\end{tabular}

Note: Statistically significant at the 10-percent $(*), 5$-percent $(* *)$, or 1-percent level $(* * *)$.

Source: Authors' calculations, using data from the 1996-2016 MEPS and the 1984-2016 FDA. 
Table 3. Reduced Form Effect of Part D on Generic Approvals

\begin{tabular}{|c|c|c|c|c|}
\hline & Minimal controls & Exclusivity & Therapeutic class & Manufacturer \\
\hline \multirow[t]{2}{*}{ Post-2003*utilization of $65+$} & $-0.193^{* *}$ & $-0.191 * *$ & $-0.202 * * *$ & $-0.227 * * *$ \\
\hline & $(0.0774)$ & $(0.0750)$ & $(0.0752)$ & $(0.0799)$ \\
\hline \multirow[t]{2}{*}{ Utilization of $65+$ pre- 2003} & $0.135 * * *$ & $0.126 * *$ & $0.201 * * *$ & $0.284 * * *$ \\
\hline & $(0.0508)$ & $(0.0492)$ & $(0.0563)$ & $(0.0624)$ \\
\hline \multirow[t]{2}{*}{ Log total spending before 2006} & $0.0514 * * *$ & $0.0498 * * *$ & $0.0557 * * *$ & $0.0577 * * *$ \\
\hline & $(0.00566)$ & $(0.00554)$ & $(0.00581)$ & $(0.00776)$ \\
\hline \multirow[t]{2}{*}{ Any exclusivity ending past year } & - & $0.115 * * *$ & $0.116 * * *$ & $0.107 * * *$ \\
\hline & & $(0.0247)$ & $(0.0242)$ & $(0.0242)$ \\
\hline \multirow[t]{2}{*}{ Any patent ending in past year } & - & $0.295 * * *$ & $0.296 * * *$ & $0.275 * * *$ \\
\hline & & $(0.0372)$ & $(0.0370)$ & $(0.0368)$ \\
\hline Year FEs & Yes & Yes & Yes & Yes \\
\hline Therapeutic class & No & No & Yes & Yes \\
\hline Manufacturer FEs & No & No & No & Yes \\
\hline
\end{tabular}

Note: Statistically significant at the 5-percent $(* *)$ or 1-percent level $(* * *)$.

Source: Authors' calculations, using data from the 1996-2016 MEPS and the 1984-2016 FDA.

Table 4. Reduced Form Effect of Part D on, and Associations of Evergreening Exclusivity and Number of Generic Competitors with, Log Drug Expenditures by Payer

\begin{tabular}{lccccc}
\hline & Total & Out of pocket & Medicaid & Medicare & Private insurer \\
\hline Post-2003*share 65+ & $-0.593^{* * *}$ & $-0.778^{* * *}$ & $-0.711^{* * *}$ & $-0.510^{* *}$ & $-0.617^{* * *}$ \\
& $(0.136)$ & $(0.144)$ & $(0.166)$ & $(0.203)$ & $(0.166)$ \\
Share 65+ pre-2003 & $0.248^{* *}$ & $0.484^{* * *}$ & 0.227 & 0.228 & $0.329 * *$ \\
& $(0.111)$ & $(0.156)$ & $(0.157)$ & $(0.207)$ & $(0.142)$ \\
Evergreening exclusivity & $0.0946^{* *}$ & $0.0794^{* *}$ & $0.0943^{* *}$ & 0.0783 & $0.146^{* * *}$ \\
& $(0.0372)$ & $(0.0339)$ & $(0.0455)$ & $(0.0477)$ & $(0.0421)$ \\
Number of generics & $-0.0903^{* * *}$ & $-0.0905^{* * *}$ & $-0.0845^{* * *}$ & $-0.0801^{* * *}$ & $-0.0720^{* * *}$ \\
Log brand price pre-generic & $(0.0142)$ & $(0.0112)$ & $(0.0156)$ & $(0.0175)$ & $(0.0149)$ \\
entry & $0.735^{* * *}$ & $0.340^{* * *}$ & $0.782^{* * *}$ & $0.807 * * *$ & $0.832^{* * *}$ \\
Year FEs & $(0.0353)$ & $(0.0388)$ & $(0.0466)$ & $(0.0593)$ & $(0.0453)$ \\
Therapeutic class & Yes & Yes & Yes & Yes & Yes \\
Manufacturer FEs & Yes & Yes & Yes & Yes & Yes \\
\hline
\end{tabular}

Note: Statistically significant at the 5-percent $(* *)$ or 1-percent level $(* * *)$.

Source: Authors' calculations, using data from the 1996-2016 MEPS and the 1984-2016 FDA. 


\section{RECENT WORKING PAPERS FROM THE CENTER FOR RETIREMENT RESEARCH AT BOSTON COLLEGE}

Is the Drop in Fertility Due to The Great Recession or a Permanent Change? Alicia H. Munnell, Anqi Chen, and Geoffrey T. Sanzenbacher, March 2019

Will Fewer Children Boost Demand for Formal Caregiving?

Gal Wettstein and Alice Zulkarnain, March 2019

The Relationship Between Occupational Requirements and SSDI Activity

Matthew S. Rutledge, Alice Zulkarnain, and Sara Ellen King, February 2019

How Does Contingent Work Affect SSDI Benefits?

Matthew S. Rutledge, Alice Zulkarnain, and Sara Ellen King, February 2019

Do Pension Cuts for Current Employees Increase Separation?

Laura D. Quinby and Gal Wettstein, January 2019

Competition, Asymmetric Information, and the Annuity Puzzle: Evidence from a Government-Run Exchange in Chile

Gastón Illanes and Manisha Padi, January 2019

Failure to Contribute: An Estimate of the Consequences of Non- and Underpayment of Self-Employment Taxes by Independent Contractors and On-Demand Workers on Social Security

Caroline Bruckner and Thomas L. Hungerford, January 2019

How Much Income Do Retirees Actually Have? Evaluating the Evidence from Five National Datasets

Anqi Chen, Alicia H. Munnell, and Geoffrey T. Sanzenbacher, November 2018

The Minimum Wage and Incentives for Full-Time Work Under the Social Security Retirement Earnings Test

Gary V. Engelhardt, October 2018

Would Greater Awareness of Social Security Survivor Benefits Affect Claiming Decisions? Anek Belbase and Laura D. Quinby, October 2018

How Does Delayed Retirement Affect Mortality and Health?

Alice Zulkarnain and Matthew S. Rutledge, October 2018

All working papers are available on the Center for Retirement Research website (https://crr.bc.edu) and can be requested by e-mail (crr@bc.edu) or phone (617-552-1762). 